\title{
Spectroscopic and fluorescence studies of diamonds from the Merlin kimberlites, Northern Territory, Australia with some comments on their recovery by $\mathrm{X}$-ray fluorescence methods
}

\author{
Wayne R. Taylor ${ }^{1,2}$ and Linda M. Glass ${ }^{3}$ \\ ${ }^{1}$ CMCA, University of Western Australia, WA 6009, Australia (pterodia@bigpond.net.au) \\ ${ }^{2}$ present address: Uramet Minerals Ltd, PO Box 8280, Subiaco East, WA 6008, Australia \\ ${ }^{3}$ Northern Territory Geological Survey, Darwin, NT 0801, Australia (linda.glass@nt.gov.au),
}

Diamonds from the Merlin kimberlite cluster, Northern Territory, Australia together with some associated alluvial stones have been characterized by FTIR spectroscopy, UV and photoluminescence microscopy and X-Ray fluorescence spectrometry.

The Merlin kimberlite cluster was emplaced into the Palaeoproterozoic North Australian Craton in Devonian times and comprises a series of 14 small diatremes most of which are diamondiferous. Open pit mining of ore began in late 1998. Until its closure in 2003, the mine produced approximately 500,000 carats from the processing of 2.4 million tonnes of ore, sourced from nine of the kimberlite pipes.

During mining operations it was found that diamond grades were about one third lower than expected from the initial test work during the exploration and feasibility phases. Following closure of the mine significant numbers of diamonds were recovered from sort-house tailings and it was suspected that there may have been problems with the X-ray recovery of Merlin stones. Early in this study it was recognized that a number of unusual diamond populations were present at Merlin. Some were considered likely candidates for showing poor X-Ray fluorescence responses including a population of high-value, fancy-yellow stones of mixed type Ib-IaA IR spectral character.

X-ray sorting or 'sortex' machines are routinely operated during mining operations to recover diamonds based on their X-ray fluorescence response, i.e. the emission of light caused by X-ray irradiation. For diamond the main emission is blue light of $\sim 450 \mathrm{~nm}$ wavelength. Recovery of diamonds by this method depends on:

- Intrinsic fluorescence of the diamond. It has been generally thought that low nitrogen abundances and low nitrogen aggregation states in diamond correlate with low X-ray fluorescence response.
- Diamond volume, i.e. size, which is proportional to weight. The fluorescent emission comes from the whole diamond volume.

- Radiation damage effects and/or surface coatings that may quench or mask the $\mathrm{X}$-ray fluorescence response

- Diamond shape may influence the "rise time", i.e. the time taken to reach peak fluorescence intensity. A delayed response may mean the diamond is not picked by the sortex machine.

- Various machine-related factors that affect performance such as flow rate of material, grain-size fraction, fluorescence threshold, photomultiplier voltage, X-ray beam intensity etc.

In order to better understand the fluorescence properties of Merlin stones in relation to specific diamond populations, $445 \sim 1 \mathrm{~mm}$ sized diamonds from the Excalibur, Launfal, Sacramore and Palomides kimberlite pipes and 100 diamonds from associated alluvials were selected for detailed investigation. The stones were handpicked from mineral concentrates at the exploration phase and so were not biased by any commercial recovery method.

FTIR spectra over the range 4000 to 600 wavenumbers were recorded with a Bruker FTIR microscope. The spectra were background corrected and processed to give nitrogen impurity content and nitrogen defect aggregation state using the methods of Mendelssohn \& Milledge (1995) and Taylor (2004). Corrections were applied for irregular platelet evolution behaviour. Results are displayed on a nitrogen aggregation diagram (Fig. 1; a plot of total nitrogen content vs. degree of A to B nitrogen defect centre aggregation). This data forms the basis of assigment of the diamonds to population groups reflecting their time-averaged thermal history (expressed by $\mathrm{T}_{\mathrm{NA}}=$ nitrogen aggregation temperature) during their residence period in the Earth's upper mantle $\left(\mathrm{t}_{\mathrm{MR}}\right)$. A series of $\mathrm{T}_{\mathrm{NA}}$ isotherm envelopes for $t_{\mathrm{MR}}=1$ to $3 \mathrm{Ga}$ are shown in Fig. 1 . 


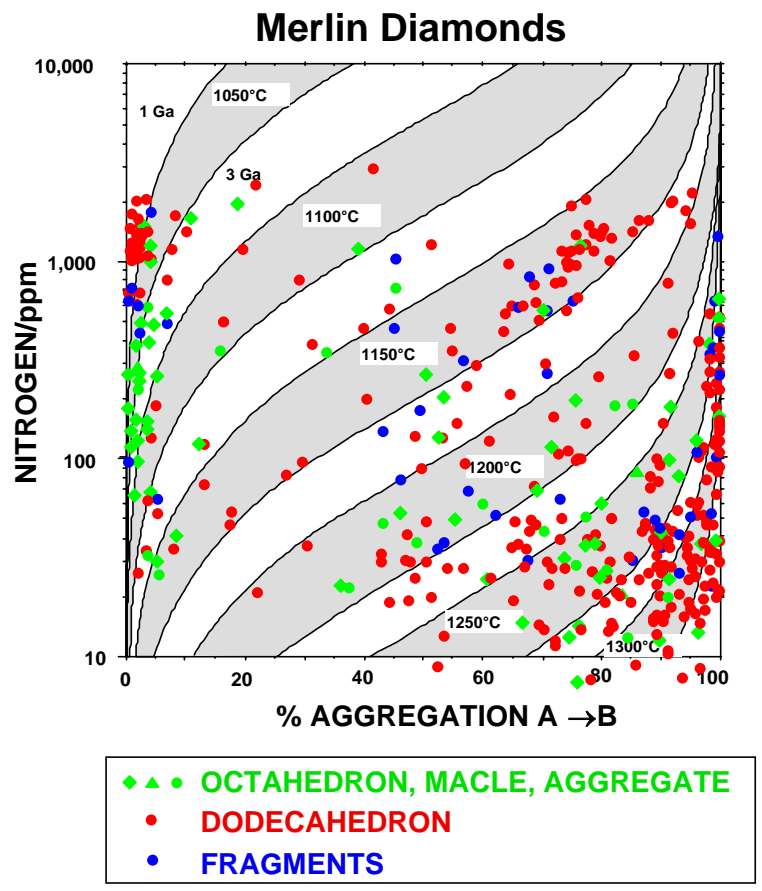

Fig. 1 Nitrogen aggregation plot for Merlin diamonds.

In Merlin there are significant low-nitrogen type IaB and IaAB populations $\left(\mathrm{T}_{\mathrm{NA}}>1200^{\circ} \mathrm{C}\right)$ together with a low aggregation IaA and mixed IaA-Ib population ( $\mathrm{T}_{\mathrm{NA}}$ $<1100^{\circ} \mathrm{C}$ ) and a high-nitrogen $\mathrm{T}_{\mathrm{NA}} \sim 1150^{\circ} \mathrm{C}$ population. The population distribution is unlike most commercial mines known world-wide. For the purposes of evaluating the fluorescence properties of Merlin diamonds, a series of IR spectroscopic groups have been defined (Fig. 2; Table 1).

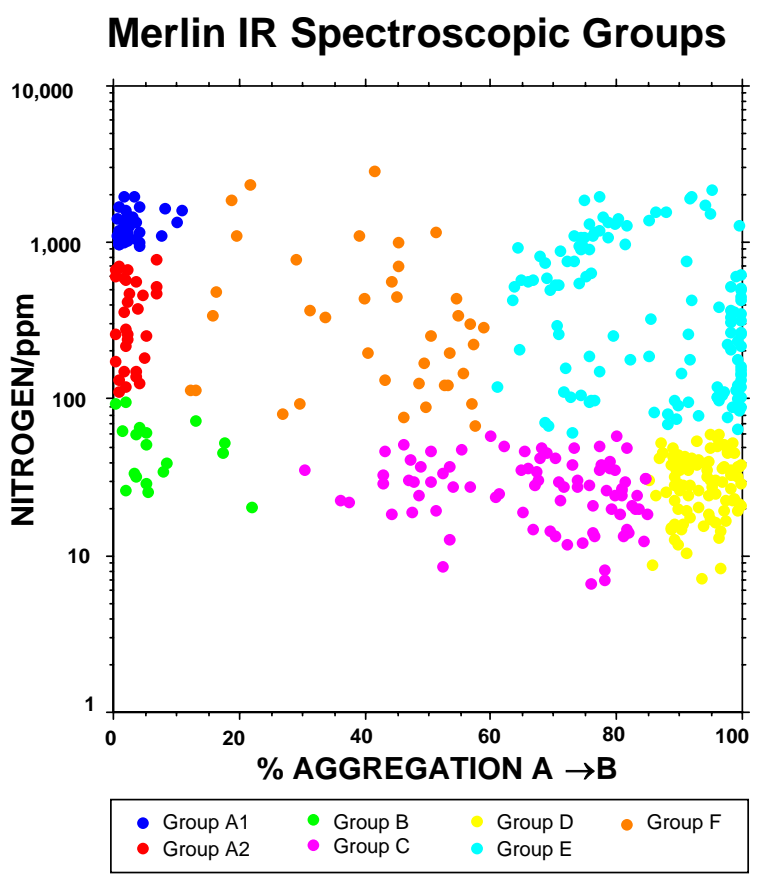

Fig. 2 IR spectroscopic groups defined on the basis of nitrogen content and aggregation state.
A subset of 172 diamonds was selected for singleparticle X-ray testing at the Ultrasort Laboratories, Perth. Diamonds were affixed to the inner spinning drum of an Ultrasort DP series X-ray sorting machine which utilises a water-cooled W-target X-ray tube operating at $24 \mathrm{~mA}$ and $48.1 \mathrm{kV}$. The machine was operated in single-channel mode with a fixed photomultiplier tube (PMT) voltage. The signal of a reference fluorescent bead together with the background reading was regularly monitored. Fluorescence measurements were signal-averaged from $\sim 20$ passes of the test diamonds. Signal intensity (PMT voltage in $\mathrm{mV}$ ), rise time and fall time were measured.

The test diamonds were examined under UV (365nm) and blue light (450nm) irradiation using a Zeiss fluorescence microscope. The resulting blue light $(\sim 450 \mathrm{~nm})$ and green light ( $\sim 530 \mathrm{~nm})$ emission imagery was recorded and an assessment of emission intensity made.

Table 1 - IR Spectroscopic Groups

\begin{tabular}{|c|c|c|l|c|l|l|}
\hline Group & Count & $\%$ & \multicolumn{1}{|c|}{ Type } & N content & $\begin{array}{c}\text { Platelet } \\
\text { Evolution }\end{array}$ & Predominant Colour \\
\hline A1 & 35 & 7.9 & IaA, Ib-IaA & $>800 \mathrm{ppm}$ & - & colourless/yellow \\
\hline A2 & 31 & 7.0 & IaA, Ib-IaA & $100-800 \mathrm{ppm}$ & - & colourless/yellow \\
\hline B & 18 & 4.0 & IaA, IaAB & $<100 \mathrm{ppm}$ & regular & colourless \\
\hline C & 85 & 19.1 & IaAB & $<60 \mathrm{ppm}$ & regular & colourless \\
\hline D & 93 & 20.9 & IaB & $<60 \mathrm{ppm}$ & irregular & colourless/brown \\
\hline E & 145 & 32.9 & IaAB, IaB & $>60 \mathrm{ppm}$ & irregular & colourless/brown \\
\hline F & 38 & 8.5 & IaAB & $>60 \mathrm{ppm}$ & regular & colourless \\
\hline Total & 445 & 100.0 & & & & \\
\hline
\end{tabular}

Results are shown in Table 2. It was found that a significant number of the Merlin high nitrogen diamonds (>1000 ppm) of low nitrogen aggregation character (virtually pure Type IaA stones) had no fluorescence response (Fig. 3). These included all the distinctive fancy-yellow diamonds from the Sacramore pipe, which contain a trace of Type Ib component giving the yellow colour.

Table 2 - X-Ray Fluorescence Freq. Distribution

\begin{tabular}{|c|c|c|c|c|c|c|c|c|}
\hline & Total \% & $\begin{array}{c}\text { Group } \\
\text { A1 \% }\end{array}$ & $\begin{array}{c}\text { Group } \\
\text { A2 }\end{array}$ & $\begin{array}{c}\text { Group B } \\
\%\end{array}$ & $\begin{array}{c}\text { Group C } \\
\%\end{array}$ & $\begin{array}{c}\text { Group D } \\
\%\end{array}$ & $\begin{array}{c}\text { Group E } \\
\%\end{array}$ & $\begin{array}{c}\text { Group F } \\
\%\end{array}$ \\
\hline $\begin{array}{c}\text { Non } \\
\text { Fluorescent }\end{array}$ & 13.5 & 85.2 & 15.4 & 0 & 0 & 0 & 0 & 0 \\
\hline $\begin{array}{c}\text { Very low } \\
\text { Fluorescence }\end{array}$ & 5.5 & 3.7 & 19.2 & 4.5 & 3.7 & 0 & 8.3 & 14.3 \\
\hline $\begin{array}{c}\text { Low } \\
\text { Fluorescence }\end{array}$ & 50 & 11.1 & 53.8 & 72.7 & 63 & 50 & 25 & 57.1 \\
\hline $\begin{array}{c}\text { Mod+High } \\
\text { Fluorescence }\end{array}$ & 31 & 0 & 11.6 & 22.8 & 33.3 & 50 & 66.7 & 28.6 \\
\hline Total & 100 & 100 & 100 & 100 & 100 & 100 & 100 & 100 \\
\hline
\end{tabular}

Of the Merlin diamonds tested, 13.5\% did not fluoresce and $5.5 \%$ showed very low X-ray fluorescence levels. Samples with moderate to high X-ray fluorescence correlate with high nitrogen aggregation levels.

Because the diamond selection tested was biased by certain groups it is necessary to re-normalise the percentages according to the actual abundance of the groups. This gives: 


\section{Merlin X-Ray Fluorescence Results}

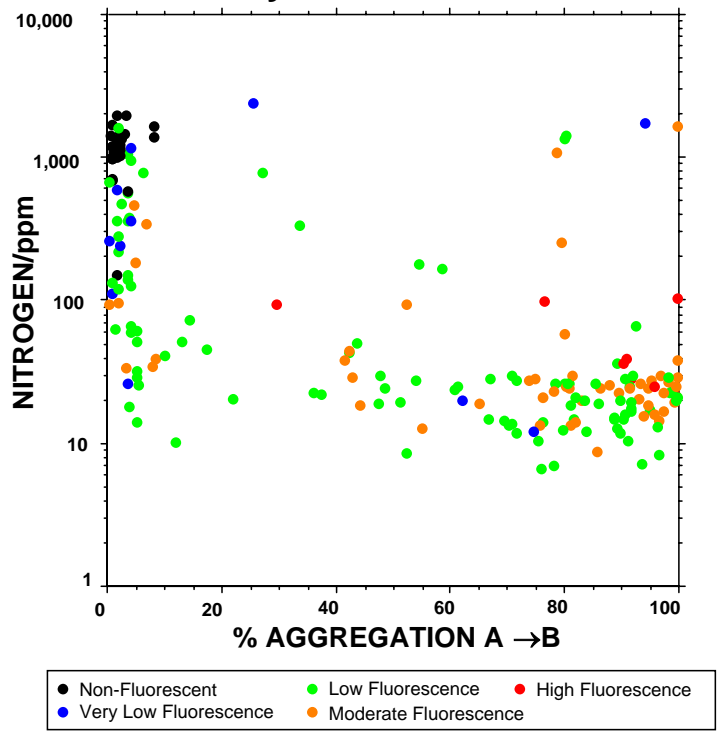

Fig. 3 Nitrogen aggregation plot categorized by X-ray fluorescence result.

Total Merlin Non-Fluorescent Stones (amplitude $<1$ $\mathrm{mV}$ per $0.1 \mathrm{ct}): \mathbf{8 . 3 \%}$

These stones would not be recovered in a sortex machine. Of these stones $45 \%$ are yellows and 55\% colourless, and $85 \%$ are dodecahedroids, $8 \%$ are octahedral and $7 \%$ are fragments. The non-fluorescent colourless stones are among the better quality Merlin stones. None of the fancy-yellows would be recovered.

Total Very Low Fluorescent Stones (amplitude 1-100 $\mathrm{mV}$ per $0.1 \mathrm{ct}): \mathbf{6 . 5 \%}$

These stones may or may not be recovered depending on stone size and machine parameters. Of these stones $73 \%$ are colourless, $18 \%$ are yellows and $9 \%$ are browns, and $45 \%$ are dodecahedroids, $45 \%$ are octahedral and $9 \%$ are fragments.

The remaining stones (85\%) are likely to be recovered by the sortex under normal operating conditions. Of these stones $89 \%$ are colourless, $8 \%$ are browns, $3 \%$ are yellows, and $73 \%$ are dodecahedroids, $20 \%$ are octahedral, $3 \%$ are fragments and $8 \%$ are aggregates or macles.

Ultraviolet (UV) fluorescence studies of Merlin diamonds show that their X-ray and UV fluorescent responses are broadly correlated, i.e. poorly UV fluorescent diamonds (Fig. 4) also show weak or nonexistent X-ray fluorescence. However, many weakly $\mathrm{X}$-ray and UV fluorescent diamonds show a strong green photoluminescence response when irradiated with blue light (Fig. 5). This suggests that other sorting techniques, such as laser-induced fluorescence using blue light lasers, could have promise in improving diamond recoveries at Merlin and elsewhere.

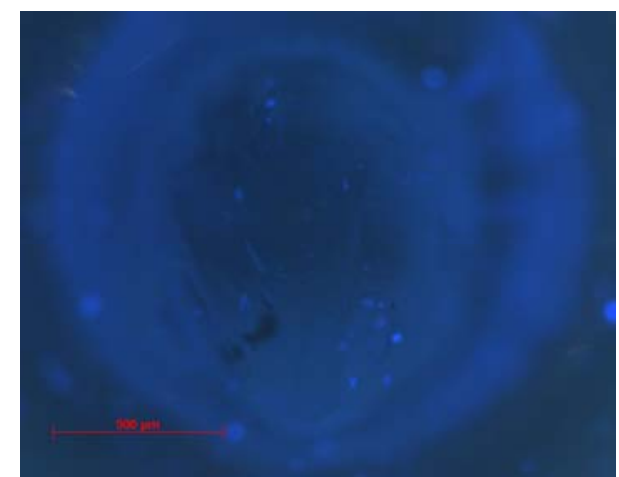

Fig. 4 Diamond M053 (low X-ray fluorescent diamond from Group D) showing extremely weak blue photoluminescence under UV light irradiation.

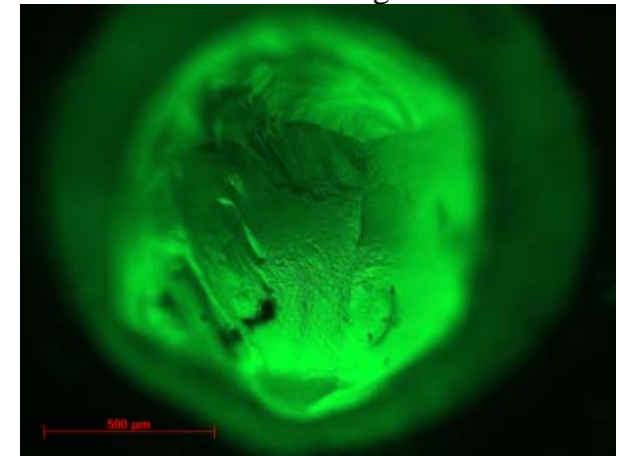

Fig. 5 Diamond M053 showing green photoluminescence under blue light irradiation.

In conclusion, a significant portion of Merlin diamonds are non-fluorescent (8\%) and this includes the distinctive fancy-yellow diamonds. These diamonds have low nitrogen aggregation states and high nitrogen contents (>1000 ppm) and would not be recovered during production using an X-ray sorting machine. In addition, a significant number (6-7\%) of diamonds exhibit very low fluorescence and depending on the threshold set for the X-ray machine, and other parameters, they may not be recovered. About half the lost grade at Merlin can therefore be ascribed to recovery issues.

Diamond recovery methods based on visible light fluorescence using the blue region of the spectrum are likely to be useful in increasing recoveries in any future mining operation at Merlin.

For any new mining operation it is recommended that careful diamond population and X-ray fluorescence studies are undertaken to determine whether recovery issues could become a problem.

References

Mendelssohn MJ \& Milledge HJ (1995) International Geology Review, 37, 95-110.

Taylor WR (2004) Rough Diamond Review, 4, 40-42. 